\title{
Neighborhood and Housing Disorder, Parenting, and Youth Adjustment in Low-Income Urban Families
}

\author{
Rosanne M. Jocson ${ }^{1}$ - Vonnie C. McLoyd ${ }^{1}$
}

Published online: 10 March 2015

(c) Society for Community Research and Action 2015

\begin{abstract}
Using two waves of data, this study examined relations among neighborhood and housing disorder, parents' psychological distress, parenting behaviors, and subsequent youth adjustment in a low-income, multiethnic sample of families with children aged 6-16. Results supported the hypothesized indirect relation between disorder and youth outcomes via parenting processes. Higher levels of neighborhood and housing disorder were associated with higher levels of parents' psychological distress, which was in turn related to more frequent use of harsh and inconsistent discipline strategies and lower parental warmth. More frequent use of harsh and inconsistent discipline was associated with higher levels of youth internalizing and externalizing behaviors 3 years later. Housing disorder contributed more strongly to parents' psychological distress than neighborhood disorder, whereas neighborhood disorder contributed more strongly to youth externalizing behaviors compared to housing disorder. Multiple-group analyses showed that the patterns of relations were similar for younger and older children, and for girls and boys.
\end{abstract}

Keywords Neighborhood disorder - Housing disorder . Parenting · Low-income families · Family stress model

\section{Introduction}

The recent financial and housing affordability crisis in the United States has renewed many researchers' interest in the impact of neighborhood and housing contexts on children

Rosanne M. Jocson rjocson@umich.edu

1 Department of Psychology, University of Michigan, 530 Church Street, Ann Arbor, MI 48109-1043, USA and adolescents from low-income families (Leventhal and Newman 2010; Murry et al. 2011). Compared to more affluent neighborhoods, the condition of low-income neighborhoods is usually characterized as lacking in basic infrastructure, with higher ambient hazards such as crime, violence, drug use, and gangs; higher physical disorder; less access to facilities and resources; and higher exposure to environmental toxins and pollutants (Caughy et al. 2012; Evans 2004). In addition, the effects of the recent affordable housing shortage is most pronounced among low-income households (National Low Income Housing Coalition 2013), leading the poorest families to live in housing units with unhealthy and unsafe conditions, including poor sanitation, inefficient heating and cooling systems, and damaged structures.

Although physical disorder in the environment has been identified as a salient risk factor for children in poverty (Evans 2004), its links to family-level factors and children's development have not been studied extensively (Brooks-Gunn et al. 2010). Moreover, very few research to date have included measures of both neighborhood and housing disorder in the same study and compared their relative contributions to parents' well-being and children's adjustment. Using longitudinal data from a multiethnic sample of low-income families living in inner-city neighborhoods, this study expands the literature on disorder and child development by examining the links among physical neighborhood and housing conditions, parents' depressive symptoms and efficacy, parental discipline and warmth, and children's subsequent internalizing and externalizing behaviors. Because previous research has suggested developmental and gender differences in the relations among these factors (Gagne and Ferrer 2006; Karriker-Jaffe et al. 2009), we further examined whether these relations differ for younger and older children, and for boys and girls. 


\section{Conceptual Model}

The family stress model (Conger et al. 2010) posits that economic hardship is related to children's outcomes partly through its detrimental effect on parents' well-being, relationships, and childrearing practices. In particular, economic hardship results in increased emotional and behavioral maladjustment in the parents, which leads to problems in parenting such as harsh, inconsistent, and uninvolved strategies, and in turn, subsequent problem behaviors and impaired competence in children. Since its initial conception, the family stress model has been empirically supported by a considerably large body of research that examined the effects of economic hardship across a wide range of family structures and cultural backgrounds (Conger et al. 2010; McLoyd et al. 2013), although some studies found limited validity among certain cultural groups (e.g., Iruka et al. 2012). Our study extends the family stress model in a multiethnic sample of lowincome families by investigating neighborhood and housing disorder as aspects of socioeconomic disadvantage that may undermine parents' and children's functioning. We proposed that neighborhood and housing disorder are related to children's internalizing and externalizing behaviors through their relations with parents' psychological distress, harsh and inconsistent discipline, and warmth (Fig. 1).

\section{Disorder and its Associations with Parenting and Child Outcomes}

\section{Neighborhood Disorder, Parenting, and Child Outcomes}

Disorder is typically characterized in terms of chaotic environmental conditions such as crowding and density, noise and confusion, and physical and social incivilities such as vandalism, abandoned and deteriorated housing or buildings, unsupervised teenagers, and gangs (Dahl et al. 2010; Brooks-Gunn et al. 2010). Previous studies that have examined neighborhood characteristics in relation to child outcomes mostly focus on neighborhood structural factors, which include macro-level and census-based indicators such as poverty and crime rate, percentage of the population with high-risk characteristics (e.g., female-headed, low income, unemployed), and ethnic heterogeneity (e.g., Hurd et al. 2012, Mrug and Windle 2009). Fewer researchers have considered the role that neighborhood disorder plays in children's well-being, although some studies have found that neighborhood disorder is related to offending behavior among adolescents (Chung and Steinberg 2006), social withdrawal among girls, and social aggression and lower social competence among boys (Caughy et al. 2012).

In accordance with the family stress model, neighborhood disorder can be detrimental to children by interfering with proximal processes such as family interactions. Everyday exposure to signs of danger and physical incivilities in the neighborhood may bring about a constant sense of distress and threat among residents, leading to feelings of powerlessness, mistrust, and social isolation (Ross and Mirowsky 2009). For parents living in disordered neighborhoods, these feelings of distress may interfere with their ability to effectively manage and care for their children, which may have corresponding consequences on their children's behaviors. Indeed, disorder and physical incivilities in the neighborhood have been associated with children's internalizing and externalizing behaviors through parental depression and less nurturing and engaging parenting strategies (Caughy et al. 2007; Mrug and Windle 2009).

\section{Housing Disorder, Parenting, and Child Outcomes}

Compared to the literature on neighborhood effects on children, research on housing and child development is relatively underdeveloped, and the mechanisms through which housing relates to children's outcomes have not yet been well-articulated (Leventhal and Newman 2010; Newman 2008). Moreover, the current literature has focused more extensively on the relations of housing quality with health-related outcomes than on children's socioemotional development (Krieger and Higgins 2002; Newman 2008). A few of the studies that examined socioemotional outcomes found that poorer housing quality is related to increased conduct and emotional problems among children (Gagne and Ferrer 2006; Gifford and Lacombe 2006). Household chaos, defined as noise, crowding, family instability, and lack of routines, has also been associated with child problem behaviors (Coldwell et al. 2006).

Similar to the mechanisms linking neighborhood disorder and child outcomes, parental functioning may be considered as a pathway through which housing disorder may predict children's socioemotional development. For example, living in chaotic and disordered households may undermine one's efficacy and sense of mastery in coping with stressful surroundings (Evans et al. 2005). Substandard housing conditions may also promote feelings of stigmatization and prevent residents from inviting guests into their homes, which can hinder social interactions and lead to social withdrawal and isolation (Krieger and Higgins 2002; Wells and Harris 2007). Moreover, the fear and anxiety brought about by living in a hazardous and disordered household may increase the risk for mental health problems (Krieger and Higgins 2002). In concordance with these arguments, poor housing quality has been related to parent psychological distress and parenting stress, which in turn were found to be associated with higher levels of socioemotional problems among children (Coley et al. 2013). 

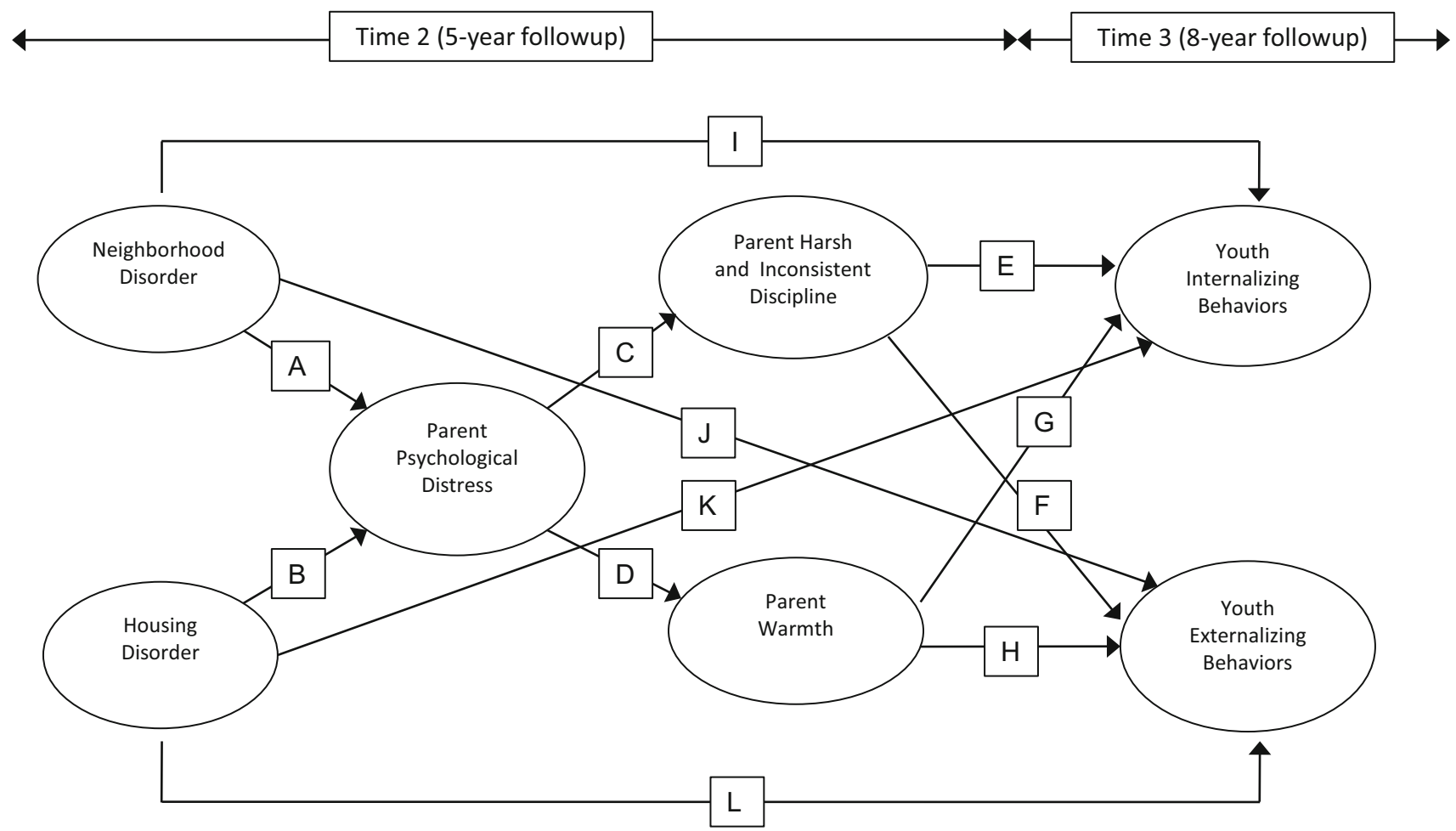

Fig. 1 Hypothesized relations between neighborhood and housing disorder, parent psychological distress, parent harsh and inconsistent discipline, parent warmth, and youth internalizing and externalizing behaviors

In view of the foregoing findings, we predicted that neighborhood and housing disorder would be indirectly related to subsequent youth behavior through parents' psychological distress and parenting behaviors. In particular, we hypothesized that (1) higher levels of neighborhood and housing disorder would predict higher levels of distress in parents (paths A and B, Fig. 1), (2) higher levels of distress, in turn, would predict parents' increased use of harsh and inconsistent discipline (path C) and lower levels of warmth (path D), (3) increased use of harsh and inconsistent discipline would predict higher levels of youth internalizing and externalizing behaviors (paths E and F), and (4) lower levels of parental warmth would predict higher levels of youth internalizing and externalizing behaviors (paths $\mathrm{G}$ and $\mathrm{H}$ ). Apart from indirect links, we also hypothesized that higher levels of neighborhood and housing disorder would directly predict higher levels of youth internalizing and externalizing behaviors (paths I, J, K, and L). We distinguished between measures of neighborhood and housing disorder to examine their relative contributions in predicting parents' well-being and youth outcomes.

\section{Age and Gender Differences}

We predicted that the relation between neighborhood and housing contexts and children's outcomes would be moderated by the child's age and gender. In particular, we examined whether the relations between perceived neighborhood and housing disorder, parents' well-being and behaviors, and children's internalizing and externalizing behaviors vary between younger (6- to 10-year-old) and older (11- to 16-yearold) children, and between boys and girls. The moderating effects of age and gender for neighborhood disorder may be different than their moderating effects for housing disorder. With regard to neighborhood disorder, it is likely that older children are more vulnerable to negative outcomes than young children because they have more opportunities to travel away from home and have increased needs for autonomy from parental control (Kroneman et al. 2004). Girls might also be more protected from the negative consequences of exposure to neighborhood physical and social disorder compared to boys because parents supervise and monitor girls more closely than boys (Kim et al. 1999). However, previous studies based on the same data set used in the current study suggest that parents in our sample were especially concerned about preventing their sons from being involved in delinquent activities (Weisner et al. 1999), making it equally plausible for boys in our sample to be less affected by negative effects of the neighborhood due to their parents' protectiveness. Regarding age and gender as moderators of the relation between housing disorder and child outcomes, it has been suggested that younger children and girls tend to spend more time at home compared to older children and boys (Kroneman et al. 2004). Increased exposure to the unfavorable conditions in the 
household could thus make younger children and girls more susceptible to negative developmental outcomes.

Empirical findings on child age and gender as moderators of the relations between neighborhood or housing contexts and child outcomes have been mixed. Some studies suggest that the influence of neighborhood and housing risk factors on children's outcomes is moderated by age and gender (e.g., Gagne and Ferrer 2006; Karriker-Jaffe et al. 2009), whereas other studies found no moderation effects (Coley et al. 2013; Gifford and Lacombe 2006). Given the discordant findings regarding the role of child age and gender as moderators, we had no specific hypothesis regarding their potential influence. As discussed, different patterns of relations may emerge depending on factors such as the timing of exposure to negative events and conditions and the nature of the parent-child relationship.

\section{Methods}

\section{Sample}

The study used data from the Child and Family Study (CFS) component of the New Hope project, a 3-year work-based antipoverty program that was implemented in two inner-city neighborhoods in Milwaukee, WI (see Huston et al. 2001, for a complete description of the New Hope project). The CFS includes 745 adults (control group $n=379$, experimental group $n=366$ ) who had one or more children between the ages of 1 and 10 at the time of random assignment. The data collection was conducted two (Time 1), five (Time 2), and eight (Time 3) years after random assignment, with participation rates of $78 \%$ at Time $1,73 \%$ at Time 2 , and $82 \%$ at Time 3 (Hardaway et al. 2012). The present analyses utilized data from Times 2 and 3, and focused on families with children aged 6 to 16 years old at Time 2. The final sample included data from 852 children (55\% African American, $29 \%$ Hispanic, $13 \%$ non-Hispanic White, and $3 \%$ American Indian or Alaskan Native; $48 \%$ female) from 556 families. Majority of the adults were female (93\%), single parents $(84 \%)$, had at least a high school education (61\%), and were receiving some form of government aid $(83 \%)$ at random assignment. Ninety percent of families who had data at Time 2 had data at Time 3. There were no significant differences in the Time 2 focal variables between families who provided data in Time 2 , and those who did not in Time 3.

\section{Measures}

\section{Demographic Characteristics}

Four demographic variables were used as covariates in all models. First, we controlled for annual family income since random assignment until the 5-year follow-up (Time 2). Annual income data were collected from administrative records, and included (1) earned income, (2) Earned Income Tax Credit, (3) Aid to Families with Dependent children cash benefits, (4) food stamps, and (5) earnings supplement for New Hope participants. Next, we also controlled for two ethnicity variables that distinguished the two biggest groups in our sample: whether the child was African American, and whether the child was Hispanic. Lastly, the New Hope program assignment of the family $(0=$ control group, $1=$ experimental group $)$ was also used as a control variable.

\section{Neighborhood Disorder (Time 2)}

Two measures of neighborhood disorder were used: interviewer reports of neighborhood problems and neighborhood ambience. Neighborhood problems were assessed using six items about whether conditions such as vacant lots, litter and garbage, vandalism, abandoned buildings, and teenagers hanging out on the street were observed within one or two blocks from the family's home. Interviewers' responses were rated on a dichotomous scale, yes (1) or no $(0)$, and were summed into a total scale $(\alpha=.87)$. The measure for neighborhood ambience included the mean of two interviewer-rated items: (1) how well kept the exteriors of the structures are in the immediate vicinity of the family's home using a 7-point scale ranging from 1 (very poorly kept) to 7 (very well kept), and (2) how pleasant and esthetically pleasing the family's neighborhood is using a 7-point scale ranging from 1 (unpleasant) to 7 (pleasant). Scores on the two items were reverse coded such that higher scores on the scale indicate poorer neighborhood ambience $(\alpha=.92)$.

\section{Housing Disorder (Time 2)}

This is a 6-item scale that included questions about the presence or absence of problems such as leaking roofs, broken windows, exposed electrical wires, and rats or mice in the home. Parents responded to the questions using a dichotomous scale, yes (1) or no (0). The scores were added to create a total score $(\alpha=.61)$, with higher scores indicating higher levels of housing disorder.

\section{Parents' Psychological Distress (Time 2)}

Two indicators of parents' psychological distress were used. Parents indicated how often they exhibited depressive symptoms (e.g., did not feel like eating, felt lonely, $1=$ rarely or none to $4=$ most or all) using the Center for Epidemiological Studies-Depression Scale (CES-D; Radloff 1977). The scores on the 20 items were averaged, with 
higher scores indicating higher levels of depressive symptoms $(\alpha=.88)$. Parental efficacy was measured using the State Hope Scale (Snyder et al. 1996). Parents indicated their agreement to six statements about agency (e.g., "I am meeting the goals I set for myself") and pathways (e.g., "I see myself as being pretty successful") using a 4-point scale ranging from 1 (strongly disagree) to 4 (strongly agree). The items were reverse-coded and averaged, with higher scores indicate lower levels of parental efficacy $(\alpha=.84)$.

\section{Parents' Harsh and Inconsistent Discipline (Time 2)}

The two measures used to indicate parents' harshness and inconsistent discipline were derived from a scale developed for an evaluation of the Self-Sufficiency Project (SSP; Morris and Michalopoulos 2000). For harsh discipline, parents indicated how often they used three discipline strategies with their child (i.e., spanking, threatening to punish, and yelling or scolding the child), using a 4-point scale ranging from 1 (never) to 4 (4 or more times). The mean of the three items was used, with higher scores indicating more frequent use of harsh discipline $(\alpha=.70)$. Inconsistent discipline was assessed by the mean of parents' ratings on five items assessing disciplinary control, $\alpha=.80$ (e.g., "Does your child get away with things that you think should have resulted in punishment?"), using a 6 -point scale $(1=$ never to $6=$ all the time $)$. Higher scores indicate more inconsistent and poorer disciplinary control over the child.

\section{Parental Warmth (Time 2)}

Parental warmth was indicated by interviewer ratings on two items $(\alpha=.87)$ taken from the Home Observation for Measurement of the Environment Scale (HOME; Caldwell and Bradley 1984). Interviewers observed brief interactions between the parent and child and indicated (1) whether the parent's voice conveyed positive feelings about the child, and (2) whether the parent spontaneously praised the child or talked about the child's good qualities or behavior, using a 3-point scale ranging from 1 (not at all) to 3 (extremely). Higher scores indicate higher levels of observed parental warmth.

\section{Youth Internalizing Behaviors (Time 3)}

Internalizing behaviors were indicated by children's mean scores on the three subscales of the Revised Children's Manifest Anxiety Scale (RCMAS; Reynolds and Richmond 1985). Children responded to five items measuring physiological anxiety, $\alpha=.68$ (e.g., "you have trouble going to sleep at night"), four items indicating worry/ oversensitivity, $\alpha=.75$ (e.g., "you are afraid of a lot of things"), and four items measuring social concerns/concentration, $\alpha=.71$ (e.g., "other children are happier than you are"), using a 5 -point scale $(1=$ never true, $5=a l$ ways true or $1=$ never, $5=$ all the time). Higher scores on the items indicate higher levels of anxiety.

\section{Youth Externalizing Behaviors (Time 3)}

Six items from the problem behavior scale of the Social Skills Rating System (SSRS; Gresham and Elliot 1990) were used as indicators of youth externalizing behaviors $(\alpha=.84)$. Parents rated how often their child displays aggressive behaviors (e.g., fights with others, talks back to adults, loses temper easily) using a 5-point scale $(1=$ never, $5=$ all the time $)$. Higher scores indicated higher levels of externalizing problems.

\section{Results}

\section{Descriptive and Bivariate Analyses}

The means, standard deviations, and correlations of the variables under investigation are presented in Table 1. All indicators within constructs were significantly correlated at $p<.01$, with $r$ s ranging from .40 to .78 (shown in boldface in Table 1). The patterns of correlations provide some preliminary support for the hypothesized relations between neighborhood and housing disorder, parent psychological distress, parent behaviors, and youth behaviors (Table 1).

\section{Structural Equation Modeling Analyses}

We tested the proposed model with structural equation modeling using maximum likelihood (ML) estimation in EQS (Bentler 2001). The model included seven latent constructs representing the focal variables in the study, specifically, neighborhood disorder, housing disorder, parent psychological distress, parents' harsh and inconsistent discipline, parental warmth, youth internalizing behaviors, and youth externalizing behaviors. The housing disorder and youth externalizing behavior variables were modeled as a latent factor with a single indicator. To account for measurement error, the error variance for each single-indicator latent factor was fixed by multiplying its variance by one minus the reliability. The model also included estimates for the effects and interrelations of four measured control variables (annual family income, African American ethnicity variable, Hispanic ethnicity variable, and New Hope participation status). To account for missing data, the estimation of the models applied the maximum likelihood method with the Yuan and Bentler (2000) 
Table 1 Means, standard deviations, and bivariate correlations of focal variables

\begin{tabular}{|c|c|c|c|c|c|c|c|c|c|c|c|c|c|c|c|}
\hline Variable & M & $\mathrm{SD}$ & 1 & 2 & 3 & 4 & 5 & 6 & 7 & 8 & 9 & 10 & 11 & 12 & 13 \\
\hline \multicolumn{16}{|l|}{ Neighborhood disorder } \\
\hline 1. Neighborhood problems & 2.49 & 1.84 & - & & & & & & & & & & & & \\
\hline 2. Poor ambience & 3.72 & 1.56 & $.67 * *$ & - & & & & & & & & & & & \\
\hline \multicolumn{16}{|l|}{ Housing disorder } \\
\hline 3. Housing problems & 0.75 & 1.15 & $.32 * *$ & $.35^{* *}$ & - & & & & & & & & & & \\
\hline \multicolumn{16}{|l|}{ Parent distress } \\
\hline 4. Depressive symptoms & 0.79 & 0.54 & $.10 *$ & $.13^{* *}$ & $.14 * *$ & - & & & & & & & & & \\
\hline 5. Poor efficacy & 1.99 & 0.54 & $.07 *$ & $.08^{*}$ & $.19 * *$ & $.40 * *$ & - & & & & & & & & \\
\hline \multicolumn{16}{|l|}{ Parent discipline } \\
\hline 6. Harsh discipline & 1.98 & 0.66 & .07 & $.10^{* *}$ & $.10 * *$ & $.24 * *$ & .07 & - & & & & & & & \\
\hline 7. Inconsistent discipline & 2.23 & 0.97 & .05 & $.15^{* *}$ & $.14 * *$ & $.41 * *$ & $.23 * *$ & $.48 * *$ & - & & & & & & \\
\hline \multicolumn{16}{|l|}{ Parent warmth } \\
\hline $\begin{array}{l}\text { 8. Positive } \\
\text { feelings }\end{array}$ & 2.41 & 0.69 & $-.10^{* *}$ & $-.20 * *$ & $-.11 * *$ & $-.16^{* *}$ & $-.16^{* *}$ & -.07 & $-.14 * *$ & - & & & & & \\
\hline 9. Praised child & 2.32 & 0.72 & $-.12 * *$ & $-.19 * *$ & $-.10 * *$ & $-.15 * *$ & $-.20 * *$ & $-.10 *$ & $-.15^{* *}$ & $.78^{* *}$ & - & & & & \\
\hline \multicolumn{16}{|l|}{ Youth internalizing behaviors } \\
\hline 10. Physiological anxiety & 2.45 & 0.80 & -.06 & -.02 & -.04 & .04 & -.02 & .07 & .03 & -.06 & -.03 & - & & & \\
\hline 11. Worry/oversensitivity & 2.41 & 0.90 & -.01 & .00 & -.03 & .04 & -.03 & .04 & .04 & -.04 & .00 & $.68 * *$ & - & & \\
\hline 12. Social concerns & 2.65 & 0.87 & -.05 & -.03 & -.04 & .06 & .00 & .05 & .05 & -.03 & -.01 & $.70 * *$ & $.56 * *$ & - & \\
\hline \multicolumn{16}{|l|}{ Youth externalizing behaviors } \\
\hline 13. Externalizing symptoms & 2.34 & 0.75 & .03 & $.12 * *$ & $.08 *$ & $.24 * *$ & $.15^{* *}$ & $.29 * *$ & $.36 * *$ & $-.15 * *$ & $-.13 * *$ & $.10 * *$ & $.08 *$ & $.12 * *$ & - \\
\hline
\end{tabular}

Pairwise $N$ ranges from 621 to 852 . Correlations of indicators within latent constructs are shown in boldface

$* p<.05 ; * * p<.01$ (two-tailed)

EM-ML imputation procedure, and the Jamshidian and Bentler (1999) robust method for adjusting standard errors. The imputation procedure resulted in a total sample of 852 cases. Because some of the variables displayed violations from normality (skewness ranged from -0.01 to 1.66 and kurtosis ranged from 0.04 to 2.26), we used the robust estimation method in EQS. To evaluate model fit, we used the Chi square test, with a nonsignificant Chi square value indicating a good-fitting model. As the Chi square test is sensitive to large sample sizes, four other indices were reported: the normed fit index (NFI), non-normed fit index (NNFI), comparative fit index (CFI), and root mean square error of approximation (RMSEA).

We first estimated the hypothesized model using the full sample, and this yielded good fit statistics (see Fig. 2). The results presented in Fig. 2 support most of the hypotheses regarding the indirect relation of neighborhood and housing disorder with youth outcomes through parenting factors (see Table 2 for a summary of total, direct, and indirect effects). Higher levels of neighborhood and housing disorder predicted higher levels of parental distress $\left(R^{2}=.14\right)$, with neighborhood disorder having a larger direct effect estimate compared to housing disorder. Parental distress, in turn, predicted more frequent use of harsh and inconsistent discipline $\left(R^{2}=.42\right)$ and lower levels of warmth $\left(R^{2}=.10\right)$. In addition, harsh and inconsistent discipline predicted both youth internalizing problems
$\left(R^{2}=.02\right)$ and youth externalizing problems $\left(R^{2}=.29\right)$. Parental warmth was unrelated to either youth outcomes. Tests of indirect effects (see Table 2) revealed that the indirect relations between neighborhood disorder and both youth internalizing and externalizing problems through parent distress and harsh and inconsistent discipline, were significant. Similarly, there were significant indirect relations between housing disorder and both youth internalizing and externalizing problems through parent distress and harsh and inconsistent discipline. In addition, higher levels of neighborhood disorder directly predicted higher levels of youth externalizing behaviors, whereas housing disorder did not have any significant direct relations with youth outcomes.

\section{Tests of Invariance Across Child Age and Gender}

We conducted multiple-group analyses to test whether the relations between neighborhood and housing disorder, parent distress, parent behaviors, and youth outcomes vary according to the child's age and gender. For the multiplegroup analysis on child age, we first tested a multiple-group model where all factor loadings, covariances, and structural paths (linking latent factors) are constrained to be equal for 6- to 10-year-olds and 11- to 16-year-olds, and compared this with a model where only the structural paths are allowed to vary across child age. The fully constrained 

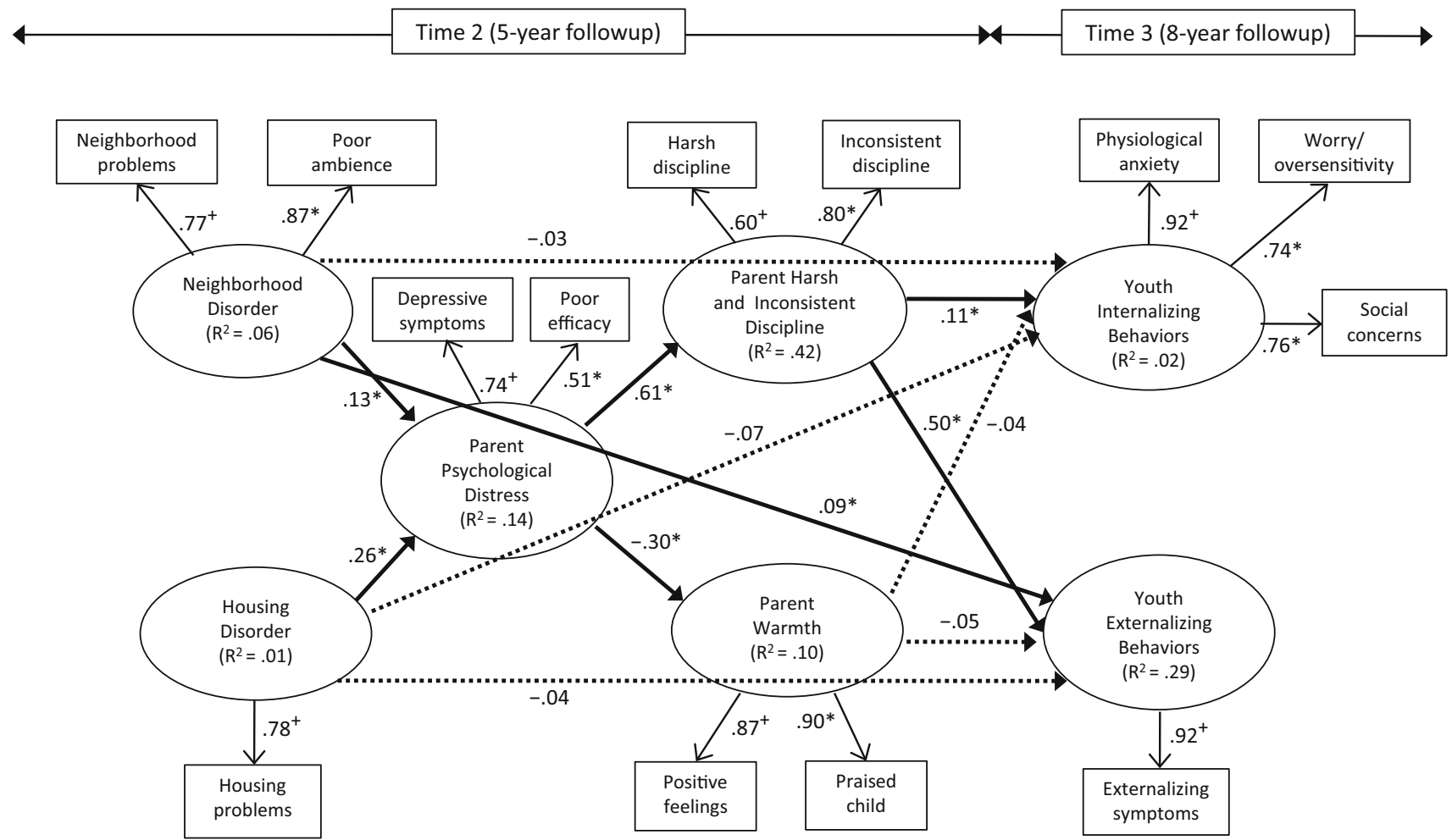

Fig. 2 Maximum likelihood estimation of the model predicting parent and youth outcomes. Model fit statistics: Yuan-Bentler scaled $\chi^{2} \quad(79, \quad N=852)=257.78, \quad p<.001 ; \quad \mathrm{NFI}=.94 \mathrm{NNFI}=.93$; $\mathrm{CFI}=.96 ; \quad \mathrm{RMSEA}=.05$. All solid paths are significant at $p<.05$. Model includes the following covariates: Time 2 annual family income, African American ethnicity, Hispanic ethnicity, New Hope participation status. *Path loading significant at $p<.05$; ${ }^{+}$variables used to set the scale for the latent construct

Table 2 Decomposition of effects for latent variable structural equation models predicting parent and youth outcomes

\begin{tabular}{|c|c|c|c|c|}
\hline Predictor & Dependent variable & Total effect & Direct effect & Indirect effect \\
\hline \multirow[t]{5}{*}{ Neighborhood disorder } & Parent psychological distress & $.13 * *$ & $.13 * *$ & - \\
\hline & Parent harsh and inconsistent discipline & $.08 * *$ & - & $.08 * *$ \\
\hline & Parent warmth & $-.04 * *$ & - & $-.04 * *$ \\
\hline & Youth internalizing behaviors & -.02 & -.03 & $.01 *$ \\
\hline & Youth externalizing behaviors & $.13 * * *$ & $.09 * *$ & $.04 * *$ \\
\hline \multirow[t]{5}{*}{ Housing disorder } & Parent psychological distress & $.26 * * *$ & $.26 * * *$ & - \\
\hline & Parent harsh and inconsistent discipline & $.16^{* * * *}$ & - & $.16 * * *$ \\
\hline & Parent warmth & $-.08 * * *$ & - & $-.08 * * *$ \\
\hline & Youth internalizing behaviors & -.05 & -.07 & $.02 *$ \\
\hline & Youth externalizing behaviors & .04 & -.04 & $.08 * * *$ \\
\hline \multirow[t]{4}{*}{ Parent psychological distress } & Parent harsh and inconsistent discipline & $.61 * * *$ & $.61 * * *$ & - \\
\hline & Parent warmth & $-.30 * * *$ & $-.30 * * *$ & - \\
\hline & Youth internalizing behaviors & $.08 * *$ & - & $.08 * *$ \\
\hline & Youth externalizing behaviors & $.32 * * *$ & - & $.32 * * *$ \\
\hline \multirow[t]{2}{*}{ Parent harsh and inconsistent discipline } & Youth internalizing behaviors & $.11 *$ & $.11 *$ & - \\
\hline & Youth externalizing behaviors & $.50 * * *$ & $.50 * * *$ & - \\
\hline \multirow[t]{2}{*}{ Parent warmth } & Youth internalizing behaviors & -.04 & -.04 & - \\
\hline & Youth externalizing behaviors & -.05 & -.05 & - \\
\hline
\end{tabular}

Tests of significance of total and indirect effects were conducted using EQS 6.0 (Bentler 2001), which uses a procedure that is based on the Sobel test (Sobel 1982). Robust estimates are reported

$* p<.05 ; * * p<.01 ; * * * p<.001$ 
model showed adequate fit, with Yuan-Bentler scaled $\chi^{2}$ (129, Ns $=382$ younger children and 470 older children $)=185.59, p<.001$, with NFI $=.94, \mathrm{NNFI}=.97$, $\mathrm{CFI}=.98$, and RMSEA $=.03$. The Chi square of the fully constrained model did not differ significantly from that of the unconstrained model, $\Delta \chi^{2}(12)=15.79, p=.201$, suggesting that paths were invariant for younger and older children. For gender, the multiple-group model with factor loadings, covariances, and structural paths constrained to be equal across girls and boys showed adequate fit, with Yuan-Bentler scaled $\chi^{2}(129, N \mathrm{~s}=412$ girls and 439 boys $)=185.59, p<.001$, with $\mathrm{NFI}=.95$, NNFI $=.99$, $\mathrm{CFI}=.99$, and RMSEA $=.02$. The Chi square of the fully constrained model did not differ significantly from that of the unconstrained model, $\Delta \chi^{2}(12)=5.76, p=.928$, likewise indicating equivalence of the structural model for boys and girls.

\section{Discussion}

This study extended the family stress model by examining neighborhood and housing disorder as aspects of socioeconomic disadvantage that relate to parents' functioning and children's adjustment in a multiethnic sample of low-income families. As hypothesized, higher levels of perceived neighborhood and housing disorder were associated with higher levels of parents' psychological distress, which was in turn related to more frequent use of harsh and inconsistent discipline and lower observed parental warmth. Higher levels of harsh and inconsistent discipline, but not warmth, were associated with higher reports of youth internalizing and externalizing symptoms. The significant associations between the variables emerged after controlling for income, ethnicity, and New Hope program status, suggesting that disorder uniquely contributes to parents' well-being and behaviors. Previous studies on crime and neighborhood risks report that women are more likely to fear crime have a higher perceived threat of victimization than men (May et al. 2010). The parents in our sample, which consists mostly of mothers living in single-parent households, may have felt a heightened sense of danger from risks that could be signaled by disordered neighborhood and housing conditions, such as broken windows, abandoned lots, and vandalism. This increased sense of danger could arguably contribute to feelings of depression and decreased motivation and efficacy, which in turn could have a negative impact on parenting behaviors and subsequent child behavior problems (Caughy et al. 2007; Coley et al. 2013).

When comparing the relative contributions of neighborhood and housing disorder, results showed that housing disorder had a stronger relation with parental distress. This suggests that although both the neighborhood and housing environment may be related to parents' well-being, parents may be more strongly distressed by disorder in more proximal contexts such as the household. The heightened level of distress may also come from concerns about not being able to adequately manage their own household, as they may feel a higher sense of ownership and responsibility toward their homes compared to their neighborhoods. In contrast, neighborhood disorder appeared to contribute more strongly to youth outcomes compared to housing disorder. In particular, neighborhood disorder directly predicted youth externalizing problems, whereas housing disorder did not have direct relations with any of the subsequent youth behaviors. This may be because the direct effect of housing disorder on children is immediate and could have dissipated across the 3-year gap between reports, whereas exposure to certain disordered neighborhood conditions (e.g., unsupervised teenagers in the streets) may also partly increase youth's access to deviant networks that could have a more lasting and pervasive influence on their behaviors. As shown in previous studies, exposure to deviant peers is one of the main factors that account for the relation between neighborhood conditions and youth externalizing behaviors (e.g., Chung and Steinberg 2006). In addition, school-aged children tend to spend a large amount of time outside the home, making the broader neighborhood environment a particularly influential context for development at this stage (Vandivere et al. 2006).

We did not find that child age and gender moderated the associations among neighborhood and housing disorder, parents' distress, parenting behaviors, and youth internalizing and externalizing problems. Because the study focused on a low-income sample, the limited variability in the neighborhood and housing disorder measures could have reduced the potential of observing significant variations in their patterns of relations with parenting and children's outcomes. However, these findings have important implications. First, they suggest that disorder, parents' distress, and harsh and inconsistent discipline are important pathways that contribute to the development of socioemotional problems in low-income children across a wide range of ages, and could therefore serve as useful targets for intervention. Second, the results suggest that although there are gender differences in the trajectories and manifestations of internalizing and externalizing problems (Crick and Zahn-Waxler 2003), these outcomes have similar patterns of associations with neighborhood, housing, and parenting risk factors for boys and girls. More studies are needed to elucidate these patterns; nonetheless, these findings call for balanced attention to the prevention of internalizing and externalizing problems in both sexes, particularly those from low-income families.

This study should be interpreted in the context of its limitations. First, although we used data from two time 
points, the inferences that could be made regarding the directionality of effects are limited. This is especially true for the relations between neighborhood and housing disorder, parents' distress, and parenting behaviors, as the measures for these variables were all collected at a single time point. Using data from a later time point to measure youth internalizing and externalizing behaviors provided a relatively stronger argument regarding the prospective influence of the neighborhood, housing, and the parenting environment on these outcomes; however, the correlational design of the study still precludes conclusions about causality. Second, measures of housing disorder, parents' psychological distress, parents' harsh and inconsistent discipline, and youth externalizing symptoms were all acquired from parent self-reports, increasing the likelihood of overestimating associations between these variables. Whereas we tried to minimize the effects of shared method variance by using observer reports for neighborhood disorder and parental warmth and youth reports for internalizing symptoms, it would have been ideal to use a multiinformant index for most of the factors examined in this study. Third, observer reports of neighborhood conditions may not necessarily match residents' own assessments of their neighborhood surroundings (Roosa et al. 2003). In addition, the measure for housing disorder did not include other aspects that may also indicate chaos and disorganization in the household, such as crowding, noise, family instability, and lack of routines. Future researchers should consider employing measures of environmental disorder that incorporate richer and more varied indicators of physical and social disorganization that could arguably influence parents' mental health and children's developmental outcomes. Finally, selection bias is a challenge that complicates interpretations of research on neighborhood and housing effects on families and children. That is, instead of these environments having effects on families and children, there may be unmeasured factors that account for the associations between the variables that were included in the analysis (Coley et al. 2013; Leventhal and Brooks-Gunn 2000). In this study, we included key control variables that are highly likely to influence the choice of neighborhoods and housing, parents' mental health and type of parenting behaviors, and child outcomes; however, a host of other factors at the individual, family, and contextual level that may influence choice of and access to neighborhood and housing (e.g., family size and structure, local housing policies, housing discrimination) should be considered in future studies.

In sum, this study is an important addition to the literature on neighborhood and housing effects on the development and functioning of low-income families and children. Whereas a significant amount of work has been devoted to examining how financial hardship, low socioeconomic standing, and other indicators of economic well-being influence children, research on the impact of both neighborhood and housing disorder on family processes and children's development is just burgeoning. Future research should identify other components of neighborhood and housing conditions that are important for parents' and children's functioning, the ways by which they interact with other developmental systems, and protective factors and processes that attenuate the negative effects of living in these contexts.

\section{References}

Bentler, P. M. (2001). EQS 6 structural equations program manual. Encino, CA: Multivariate Software.

Brooks-Gunn, J., Johnson, A. D., \& Leventhal, T. (2010). Disorder, turbulence, and resources in children's homes and neighborhoods. In G. W. Evans \& T. D. Wachs (Eds.), Chaos and its influence on children's development: An ecological perspective (pp. 155-170). Washington DC: American Psychological Association.

Caldwell, B. M., \& Bradley, R. H. (1984). Home observation for the measurement of the environment (Rev ed.). Little Rock: University of Arkansas.

Caughy, M. O., Franzini, L., Windle, M., Dittus, P., Cuccaro, P., Elliott, M. N., \& Schuster, M. A. (2012). Social competence in late elementary school: Relationships to parenting and neighborhood context. Journal of Youth and Adolescence, 41, 1613-1627.

Caughy, M. O., Nettles, S. M., \& O’Campo, P. J. (2007). Community influences on adjustment in first grade: An examination of an integrated process model. Journal of Child and Family Studies, $16,819-836$.

Chung, H. L., \& Steinberg, L. (2006). Relations between neighborhood factors, parenting behaviors, peer deviance, and delinquency among serious juvenile offenders. Developmental Psychology, 42, 319-331.

Coldwell, J., Pike, A., \& Dunn, J. (2006). Household chaos-Links with parenting and child behavior. Journal of Child Psychology and Psychiatry, 47, 1116-1122.

Coley, R. L., Leventhal, T., Lynch, A. D., \& Kull, M. (2013). Relations between housing characteristics and the well-being of low-income children and adolescents. Developmental Psychology, 49, 1775-1789.

Conger, R. D., Conger, K. J., \& Martin, M. J. (2010). Socioeconomic status, family processes, and individual development. Journal of Marriage and the Family, 72, 685-704.

Crick, N. R., \& Zahn-Waxler, C. (2003). The development of psychopathology in females and males: Current progress and future challenges. Development and Psychopathology, 15, 719-742.

Dahl, T., Ceballo, R., \& Huerta, M. (2010). In the eye of the beholder: Mothers' perceptions of poor neighborhoods as places to raise children. Journal of Community Psychology, 38, 419-434.

Evans, G. W. (2004). The environment of childhood poverty. American Psychologist, 59, 77-92.

Evans, G. W., Gonnella, C., Marcynyszyn, L. A., Gentile, L., \& Salpekar, N. (2005). The role of chaos in poverty and children's socioemotional adjustment. Psychological Science, 16, 560-565. 
Gagne, L. G., \& Ferrer, A. (2006). Housing, neighborhoods, and development outcomes of children in Canada. Canadian Public Policy, 32, 275-300.

Gifford, R., \& Lacombe, C. (2006). Housing quality and children's socioemotional health. Journal of Housing and the Built Environment, 21, 177-189.

Gresham, F. M., \& Elliot, S. N. (1990). Social skills rating system manual. Circle Pines, MN: American Guidance Service.

Hardaway, C. R., McLoyd, V. C., \& Wood, D. (2012). Exposure to violence and socioemotional adjustment in low-income youth: An examination of protective factors. American Journal of Community Psychology, 49, 112-126.

Hurd, N. M., Stoddard, S. A., \& Zimmerman, M. A. (2012). Neighborhoods, social support, and African American adolescents' mental health outcomes: A multilevel path analysis. Child Development, 84, 858-874.

Huston, A. C., Duncan, G. J., Granger, R., Bos, J., McLoyd, V. C., Mistry, R., \& Ventura, A. (2001). Work-based antipoverty programs for parents can enhance the school performance and social behavior of children. Child Development, 72, 318-336.

Iruka, I. U., LaForett, D. R., \& Odom, E. C. (2012). Examining the validity of the family investment and stress models and relationship to children's school readiness across five cultural groups. Journal of Family Psychology, 26, 359-370.

Jamshidian, M., \& Bentler, P. M. (1999). ML estimation of mean and covariance structures with missing data using complete data routines. Journal of Education and Behavioral Statistics, 24, 21-41.

Karriker-Jaffe, K. J., Foshee, V. A., Ennett, S. T., \& Suchindran, C. (2009). Sex differences in the effects of neighborhood socioeconomic disadvantage and social organization on rural adolescents' aggression trajectories. American Journal of Community Psychology, 43, 189-203.

Kim, J. E., Hetherington, E. M., \& Reiss, D. (1999). Associations among family relationships, antisocial peers, and adolescents' externalizing behaviors: Gender and family type differences. Child Development, 70, 1209-1230.

Krieger, J., \& Higgins, D. L. (2002). Housing and health: Time again for public health action. American Journal of Public Health, 92, 758-768.

Kroneman, L., Loeber, R., \& Hipwell, A. E. (2004). Is neighborhood context differently related to externalizing problems and delinquency for girls compared with boys? Clinical Child and Family Psychology Review, 7, 109-112.

Leventhal, T., \& Brooks-Gunn, J. (2000). The neighborhoods they live in: The effects of neighborhood residence on child and adolescent outcomes. Psychological Bulletin, 126, 309-337.

Leventhal, T., \& Newman, S. (2010). Housing and child development. Child and Youth Services Review, 32, 1165-1174.

May, D. C., Rader, N. E., \& Goodrum, S. (2010). A gendered assessment of the "threat of victimization": Examining gender differences in fear of crime, perceived risk, avoidance, and defensive behaviors. Criminal Justice Review, 35, 159-182.

McLoyd, V. C., Mistry, R. S., \& Hardaway, C. R. (2013). Poverty and children's development: Familial processes as mediating influences. In E. Gershoff, R. Mistry, \& D. Crosby (Eds.), Societal contexts of child development: Pathways of influence and implications for practice and policy (pp. 109-124). New York: Oxford University Press.

Morris, P., \& Michalopoulos, C. (2000). The Self-Sufficiency Project at 36 months: Effects on children of a program that increased employment and income. New York: Manpower Demonstration Research Corporation.

Mrug, S., \& Windle, M. (2009). Mediators of neighborhood influences on externalizing behavior in preadolescent children. Journal of Abnormal Child Psychology, 37, 265-280.

Murry, V. M., Berkel, C., Gaylord-Harden, N. K., Copeland-Linder, N., \& Nation, M. (2011). Neighborhood poverty and adolescent development. Journal of Research on Adolescence, 21, 114-128.

National Low Income Housing Coalition. (2013). America's affordable housing shortage, and how to end it. Housing Spotlight, 3, 1-6.

Newman, S. J. (2008). Does housing matter for poor families? A critical summary of research and issues still to be resolved. Journal of Policy Analysis and Management, 27, 895-925.

Radloff, L. S. (1977). The CES-D scale: A self-report depression scale for research in the general population. Applied Psychological Measurement, 1, 385-401.

Reynolds, C. R., \& Richmond, B. O. (1985). Revised children's manifest anxiety scale: Manual. Los Angeles, CA: Western Psychological Services.

Roosa, M. W., Jones, S., Tein, J. Y., \& Cree, W. (2003). Prevention science and neighborhood influences on low-income children's development: Theoretical and methodological issues. American Journal of Community Psychology, 31, 55-72.

Ross, C. E., \& Mirowsky, J. (2009). Neighborhood disorder, subjective alienation, and distress. Journal of Health and Social Behavior, 50, 49-64.

Snyder, C. R., Sympson, S. C., Ybasco, F. C., Borders, T. F., Babyak, M. A., \& Higgins, R. L. (1996). Development and validation of the State Hope scale. Journal of Personality and Social Development, 70, 321-335.

Sobel, M. E. (1982). Asymptotic confidence intervals for indirect effects in structural equation models. Sociological Methodology, 13, 290-312.

Vandivere, S., Hair, E. C., Theokas, C., Cleveland, K., McNamara, M., \& Atienza, A. (2006). How housing affects child well-being. Coral Gables, FL: Funders Network for Smart Growth and Livable Communities.

Weisner, T. S., Bernheimer, L., Espinosa, V., Gibson, C., Howard, E., \& Magnuson, K. (1999). From the living rooms and daily routines of the economically poor: An ethnographic study of the New Hope effects on families and children. Paper presented at the meeting of the Society for Research in Child Development, Albuquerque, NM.

Wells, N. M., \& Harris, J. D. (2007). Housing quality, psychological distress, and the mediating role of social withdrawal: A longitudinal study of low-income women. Journal of Environmental Psychology, 27, 69-78.

Yuan, K. H., \& Bentler, P. M. (2000). Three likelihood-based methods for mean and covariance structure analysis with nonnormal missing data. Sociological Methodology, 30, $165-200$. 